Journal of

Molecular Microbiology

and Biotechnology
J Mol Microbiol Biotechnol 2007;12:131-138

DOI: $10.1159 / 000096468$

\title{
Nitrogen Metabolism and Nitrogen Control in Corynebacteria: Variations of a Common Theme
}

\author{
Britta Walter ${ }^{a, b}$ Eva Hänssler ${ }^{a}$ Jörn Kalinowski ${ }^{c} \quad$ Andreas Burkovski ${ }^{a}$ \\ ${ }^{a}$ Lehrstuhl für Mikrobiologie, Friedrich-Alexander-Universität Erlangen-Nürnberg, Erlangen; ${ }^{b}$ Institut für \\ Biochemie, Universität zu Köln; ' Institut für Genomforschung, Centrum für Biotechnologie (CeBiTec), \\ Universität Bielefeld, Bielefeld, Germany
}

\section{Key Words}

Ammonium - Corynebacterium - Glutamine synthetase • Nitrogen control $\cdot$ Nitrogen regulation

\begin{abstract}
The published genome sequences of Corynebacterium diphtheriae, Corynebacterium efficiens, Corynebacterium glutamicum and Corynebacterium jeikeium were screened for genes encoding central components of nitrogen source uptake, nitrogen assimilation and nitrogen control systems. Interestingly, the soil-living species C. efficiens and C. glutamicum exhibit a broader spectrum of genes for nitrogen transport and metabolism than the pathogenic species $C$. diphtheriae and $C$. jeikeium. The latter are characterized by gene decay and loss of functions like urea metabolism and nitrogen-dependent transcription control. The global regulator of nitrogen regulation AmtR and its DNA-binding motif are conserved in C. diphtheriae, C. efficiens and C. glutamicum, while in C. jeikeium, an AmtR-encoding gene as well as putative AmtR-binding motifs are missing.
\end{abstract}

\section{Introduction}

Almost all of the macromolecules in a bacterial cell, e.g. proteins, nucleic acids and cell wall components, contain nitrogen. Thus, prokaryotes have developed elaborate mechanisms to provide an optimal nitrogen supply for metabolism and to overcome and survive situations of nitrogen starvation. This communication focuses on nitrogen metabolism in corynebacteria. The first member of the genus, Corynebacterium diphtheriae, was described at the end of the 19th century [Lehmann and Neumann, 1896] and today approximately 100 Corynebacterium species and subspecies have been identified (http://www. dsmz.de/microorganisms/bacterial_nomenclature_info. php ?genus $=$ Corynebacterium \&show_all_details $=1$ ) .

The uptake and assimilation of nitrogen sources in corynebacteria has been investigated intensively for the amino acid producer Corynebacterium glutamicum and a considerable number of uptake systems for nitrogen sources as well as assimilatory pathways and regulatory proteins were identified and characterized (for reviews, see Burkovski [2003a, b, 2005]). Based on these functional data, we compared nitrogen assimilation and nitrogen control systems of four Corynebacterium species with published genome sequence, i.e. C. diphtheriae [CerdenoTarraga et al., 2003], C. efficiens [Fudou et al., 2002], C. glutamicum [Ikeda and Nakagawa, 2003; Kalinowski et

Andreas Burkovsk

Lehrstuhl für Mikrobiologie, Friedrich-Alexander-Universität Erlangen-Nürnberg Staudtstrasse 5, DE-91058 Erlangen (Germany)

Tel. +49 9131852 8086, Fax +49 91318528082

E-Mail aburkov@biologie.uni-erlangen.de 
Table 1. Corynebacterial genes and proteins involved in nitrogen uptake, assimilation and control

\begin{tabular}{|c|c|c|c|c|c|}
\hline \multirow[t]{2}{*}{ Gene } & \multirow[t]{2}{*}{ Function (in C. glutamicum) } & \multicolumn{4}{|c|}{ Species $^{\mathrm{a}}$} \\
\hline & & Cdi & Cef & $\mathrm{Cgl}$ & Cje \\
\hline$a m t A$ & ammonium uptake system [Siewe et al., 1996] & - & + & + & - \\
\hline$a m t B$ & ammonium uptake system [Meier-Wagner et al., 2001] & - & + & + & + \\
\hline$a m t R$ & transcription regulator [Jakoby et al., 2000] ${ }^{\mathrm{b}}$ & + & + & + & - \\
\hline $\operatorname{cod} A$ & creatinine deaminase [Bendt et al., 2004] & - & - & + & - \\
\hline $\operatorname{crnT}$ & creatinine permease [Bendt et al., 2004] & - & - & + & - \\
\hline$g d h$ & glutamate dehydrogenase [Börmann et al., 1992] & + & $+^{\mathrm{c}}$ & + & + \\
\hline $\ln A$ & glutamine synthetase, GS I- $\beta$ type [Jakoby et al., 1997] & - & $+^{c}$ & + & + \\
\hline$g \ln A 2$ & glutamine synthetase, GS I- $\alpha$ type [Nolden et al., 2001b] & + & + & + & + \\
\hline$g \ln D$ & $\begin{array}{l}\text { GlnK-regulating adenylyltransferase [Jakoby et al., 1999; } \\
\text { Nolden et al., 2001b; Strösser et al., 2004] }\end{array}$ & + & + & + & - \\
\hline$g \ln E$ & GS-regulating adenylyltransferase [Nolden et al., 2001b] & + & + & + & + \\
\hline$g \ln K$ & signal transduction protein [Jakoby et al., 1999; Nolden et al., 2001b] & + & + & + & + \\
\hline$g l t B$ & glutamate synthase subunit [Beckers et al., 2001; Schulz et al., 2001] & - & + & + & + \\
\hline gltD & glutamate synthase subunit [Beckers et al., 2001; Schulz et al., 2001] & - & + & + & + \\
\hline ureA & urease subunit [Nolden et al., 2000; Puskás et al., 2000] & - & + & + & - \\
\hline ureB & urease subunit [Nolden et al., 2000; Puskás et al., 2000] & - & + & + & - \\
\hline ureC & urease subunit [Nolden et al., 2000; Puskás et al., 2000] & - & + & + & - \\
\hline ureD & urease subunit [Nolden et al., 2000; Puskás et al., 2000] & - & + & + & - \\
\hline ureE & urease subunit [Nolden et al., 2000; Puskás et al., 2000] & - & + & + & - \\
\hline ureF & urease subunit [Nolden et al., 2000; Puskás et al., 2000] & - & + & + & - \\
\hline ureG & urease subunit [Nolden et al., 2000; Puskás et al., 2000] & - & + & + & - \\
\hline ureR & putative regulator of urease genes [Beckers et al., 2004] & - & - & + & - \\
\hline urtA & subunit of urease uptake system [Beckers et al., 2004] & - & + & + & - \\
\hline urtB & subunit of urease uptake system [Beckers et al., 2004] & - & + & + & - \\
\hline urtC & subunit of urease uptake system [Beckers et al., 2004] & - & + & + & - \\
\hline urtD & subunit of urease uptake system [Beckers et al., 2004] & - & + & + & - \\
\hline urtE & subunit of urease uptake system [Beckers et al., 2004] & - & + & + & - \\
\hline
\end{tabular}

al., 2003] and C. jeikeium [Tauch et al., 2005] (for a global comparison of these genomes, see Kalinowski [2005]).

\section{Results and Discussion}

\section{Genes Encoding Proteins Involved in Nitrogen}

Metabolism and Nitrogen Control in Corynebacteria

The available corynebacterial genome sequences at the NCBI genomes database (http://www.ncbi.nlm.nih.gov/ genomes/lproks.cgi) were screened for genes involved in the uptake of nitrogen sources, their metabolism and nitrogen control. On the basis of components already characterized in C. glutamicum, the comparison of the differ- ent species revealed that C. glutamicum and C. efficiens have a broader spectrum of genes encoding proteins involved in nitrogen metabolism than $C$. diphtheriae and C. jeikeium, species which are characterized by a loss of various genes (table 1). A gdh gene encoding glutamate dehydrogenase was annotated in all species. The same is true for $g \ln A 2$ encoding a GS I- $\alpha$ type glutamine synthetase. Interestingly, a typical high-affinity ammonium assimilation GS/GOGAT pathway consisting of GS I- $\beta$ type glutamine synthetase and glutamate synthase (GOGAT) seems to be absent in C. diphtheriae. This is correlated with a reduced number of ammonium transport proteins in this organism. While two genes encoding ammonium transporters are present in C. glutamicum and C. efficiens (amtA and $a m t B$ ), C. jeikeium has one of 
Table 2. Corynebacterial genes and proteins with predicted functions in nitrogen uptake, nitrogen assimilation and nitrate/nitrate usage

\begin{tabular}{|c|c|c|c|c|c|}
\hline \multirow[t]{2}{*}{ Gene } & \multirow[t]{2}{*}{ Predicted function } & \multicolumn{4}{|c|}{ Species $^{\mathrm{a}}$} \\
\hline & & Cdi & Cef & $\mathrm{Cgl}$ & Cje \\
\hline$g l s K$ & glutaminase & - & + & + & - \\
\hline narI & respiratory nitrate reductase $\gamma$ chain & + & + & + & - \\
\hline narJ & nitrate reductase $\delta$ chain & + & + & + & - \\
\hline narH & respiratory nitrate reductase oxidoreductase & + & + & + & - \\
\hline narG & nitrate reductase $\alpha$ subunit & + & + & + & - \\
\hline narK & nitrate/nitrite transporter, nitrite extrusion protein & $+{ }^{b}$ & + & + & - \\
\hline c & ferredoxin-nitrite reductase & - & + & - & - \\
\hline c & nitrate transport ATP binding protein & - & + & - & - \\
\hline c & nitrate transport permease protein & - & + & - & - \\
\hline c & nitrate transport protein & - & + & - & - \\
\hline c & nitrate transport protein & - & + & - & - \\
\hline c & urea carboxylase & - & $+{ }^{b}$ & - & - \\
\hline
\end{tabular}

these genes (amtB) while no amt gene was annotated in $C$. diphtheriae. Urease-encoding genes were only annotated in C. efficiens and C. glutamicum. In these species also genes encoding a urea uptake system were found. Based on the genome data, the previously reported observation of urease activity in a non-virulent $C$. diphtheriae strain is doubtful [Nolden et al., 2002]. The ureR gene encoding a putative regulator of urease operon transcription was present in C. glutamicum only. However, an effect of a knock-out mutation was not observed [Beckers et al., 2004]. The gene is missing in C. efficiens. The crnT gene, coding for a creatinine uptake system, and $\operatorname{cod} A$, encoding a creatinine deaminase, were only annotated in C. glutamicum; this nitrogen source seems to be exclusively metabolized by this species. Besides the mentioned uptake and assimilation proteins, the presence of a number of regulatory proteins can be predicted. A glutamine synthetase-regulating adenylyltransferase encoded by $g \ln E$ and a $\mathrm{P}_{\mathrm{II}}$-type signal transduction protein encoded by the $g \ln K$ gene was observed in all organisms. Interestingly, a gene encoding the master regulator of nitrogendependent transcription control, AmtR, and a $g \ln D$ gene encoding the GlnK-modifying enzyme was found in all species besides $C$. jeikeium, where these seem to be absent.

Based on the annotations of putative proteins (table 2), the presence of a glutaminase enzyme (encoded by $g l s K$ ) can be predicted in C. efficiens and C. glutamicum. Besides the urease, two urea carboxylases are annotated for
C. efficiens in addition to a second glutamate dehydrogenase-encoding gene. Furthermore, the annotation of the narIJHG gene cluster indicates that C. diphtheriae, C. efficiens as well as C. glutamicum might have the potential to use nitrate reduction for energy generation. However, the annotation of various genes for nitrate uptake systems might indicate that $C$. efficiens is best equipped for anaerobic nitrate and nitrite respiration, while transport might be limiting in C. glutamicum.

\section{Conservation of AmtR-Binding Motifs}

AmtR was identified as the master regulator of nitrogen control in C. glutamicum and its binding sites were characterized upstream of genes transcribed in response to nitrogen starvation [Beckers et al., 2005]. The AmtR protein is highly conserved in C. efficiens (86\% identical amino acids) and $C$. diphtheriae (70\% identical amino acids), while it is absent in C. jeikeium [Brune et al., 2005]. We used the C. glutamicum AmtR-binding motif to screen the C. diphtheriae, C. efficiens and C. jeikeium genome for putative AmtR-binding sites. In fact, a number of genes which are connected to nitrogen metabolism and which are nitrogen-regulated in C. glutamicum were identified in the AmtR-exhibiting strains $C$. diphtheriae and C. efficiens by this approach. For C. diphtheriae, these include the $g \ln A 2$ and $g d h$ gene, for C. efficiens, the $g \ln A$ gene and the $g l t B D, a m t B-g \ln K-g \ln D$, amt $A$-ocd-sox $A$ and ure $A B C E F G D$ gene cluster. From the data obtained, species-specific AmtR-binding motifs were generated, which 


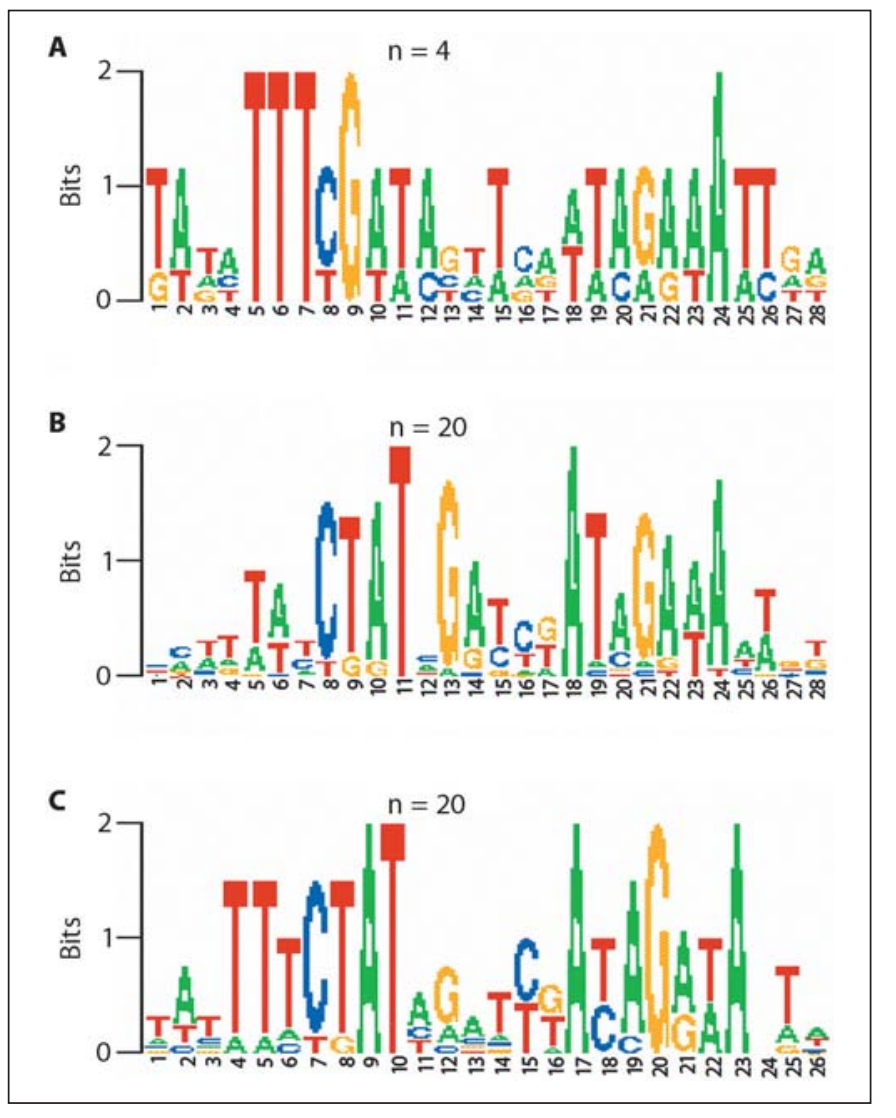

Fig. 1. AmtR-binding motifs for C. diphtheriae (A), C. efficiens (B) and C. glutamicum (C) represented by sequence logo plots. Depending on the number of putative AmtR-regulated genes, the AmtR box in $C$. diphtheriae was composed of 4 DNA sequences, while the boxes for C. efficiens and C. glutamicum were generated from 20 sequences.

show some variations compared to the C. glutamicum AmtR box (fig. 1). In contrast, searches in C. jeikeium gave no significant results (data not shown), which is in accord with the absence of an $a m t R$ gene in this bacterium.

\section{Analysis of Nitrogen-Dependent Transcription}

From the genome data, predictions about nitrogen control in the different species were possible. It was already shown that nitrogen control in $C$. diphtheriae is regulated by an AmtR-dependent mechanism as found in C. glutamicum [Nolden et al., 2002]. While AmtR is conserved in C. diphtheriae, C. efficiens and C. glutamicum, the lack of an $a m t R$ gene homolog as well as the lack of a $\operatorname{gln} D$ gene, which was shown to be essential for nitrogen signal transduction in C. glutamicum [Nolden et al., 2001a; Strösser et al., 2004] gave rise to the idea that $C$.

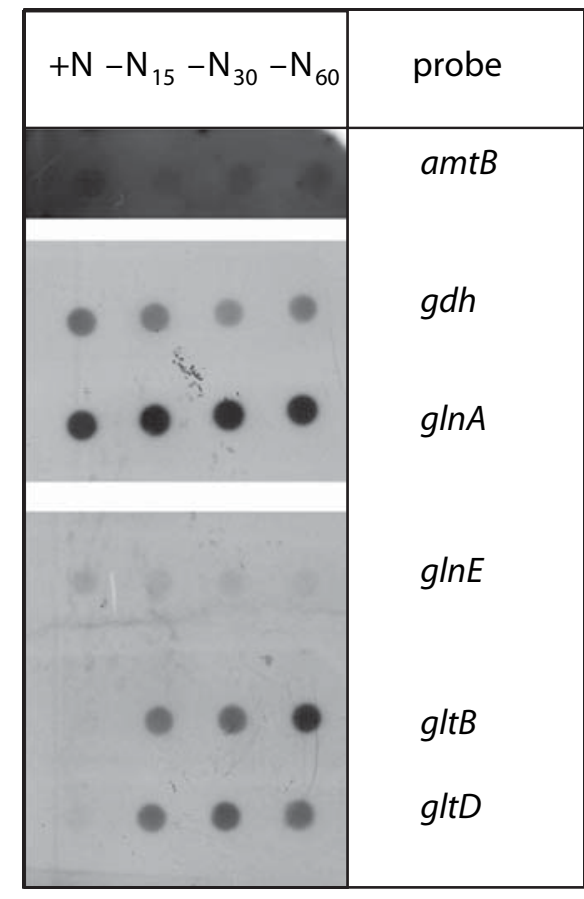

Fig. 2. Transcription of genes encoding proteins involved in ammonium uptake and assimilation in C. jeikeium. RNA was isolated from cells grown in BYT medium and from cells incubated in nitrogen-free minimal medium. Samples were hybridized with the indicated digoxigenin-labeled antisense probes. Since the $a m t B$ hybridization revealed very low signal intensity, exposition of the X-ray film was carried out overnight. Dot blots of all other probes were exposed for 5-15 $\mathrm{min}$.

jeikeium does not have a nitrogen control system. To test this hypothesis, RNA hybridization experiments were carried out. C. jeikeium cells were grown in nitrogen-rich BYT medium, samples for RNA preparation were taken and remaining cells were transferred to prewarmed $C$. glutamicum minimal medium without nitrogen source as described in a previous publication for $C$. diphtheriae [Nolden et al., 2002]. After 15, 30 and 60 min of incubation, samples were taken. RNA preparations were hybridized with probes directed against $a m t B, g d h, g \ln A, g \ln E$, $g l t B$ and $g l t D$ (fig. 2). These experiments indicated that $a m t B$ is expressed, although at very low level, up-regulation of transcription in response to nitrogen starvation was not observed. A significant up-regulation of expression in response to nitrogen deprivation was also not observed for $g d h, g \ln A$ and $g \ln E$. Only $g l t B$ and $g l t D$ expression was strongly induced upon starvation. On the first glance, this result seems to hint to an AmtR-independent nitrogen control mechanism of $g l t B D$ transcription. However, further studies are necessary to examine whether 
this is a specific effect of nitrogen deprivation or the result of general starvation or growth limitation response.

\section{Analysis of Ammonium Uptake}

In order to verify the genome annotations and especially total the absence of ammonium-transporter-encoding amt genes in C. diphtheriae, transport measurements were carried out. Uptake of the $\left[{ }^{14} \mathrm{C}\right]$-labeled ammonium analog methylammonium was determined for cells supplied with nitrogen and for nitrogen-deprived cells. To address the question of different substrate affinities, low $(100 \mu \mathrm{M})$, medium $(500 \mu \mathrm{M})$ and high $(1,000 \mu \mathrm{M})$ methylammonium concentrations were used.

For $C$. diphtheriae, no methylammonium transport was detectable, which is in accordance with the absence of an ammonium transporter-encoding amt gene in this organism. Astonishingly, also C. jeikeium revealed no methylammonium uptake, although RNA hybridization experiments hint to an at least low-level expression of the ammonium transporter-encoding $a m t B$ gene (fig. 2). Either the C. jeikeium AmtB transporter is highly selective for ammonium and the substrate analog $\left[{ }^{14} \mathrm{C}\right]$-methylammonium is not recognized, or the protein is not synthesized in sufficient amounts or it is inactive. In C. efficiens and C. glutamicum, an identical pattern of methylammonium uptake was observed. Transport was not detectable, when cells were grown in nitrogen-rich BHI medium. This is in accord with the repression of amt $A$ and $a m t B$ transcription by $A m t R$. In response to nitrogen starvation, the transporters are synthesized (for C. glutamicum data, see Meier-Wagner et al. [2001] and Beckers et al. [2005]) and uptake occurs. In general, the transporters of C. efficiens have a lower activity compared to those of C. glutamicum, and also their affinity seems to be lower. In the presence of $100 \mu \mathrm{M}$ methylammonium a transport rate of $0.5 \pm 0.6 \mathrm{nmol} \mathrm{min}{ }^{-1}$ (mg dry weight) ${ }^{-1}$ was determined for C. efficiens and $6.5 \pm 0.8 \mathrm{nmol} \mathrm{min}^{-1}(\mathrm{mg}$ dry weight $)^{-1}$ for C. glutamicum. In the two species, uptake rates increased with higher substrate concentration $(500$ and $1,000 \mu \mathrm{M})$ to $5.0 \pm 2.2$ and $6.9 \pm 2.3 \mathrm{nmol}$ $\mathrm{min}^{-1}$ (mg dry weight) ${ }^{-1}$ in C. efficiens and to $9.3 \pm 1.1$ and $11.6 \pm 0.4 \mathrm{nmol} \mathrm{m^{-1 }}(\mathrm{mg} \text { dry weight })^{-1}$ in C. glutamicum.

\section{Regulation of Glutamine Synthetase Activity}

As in the case of methylammonium transport, glutamine synthetase activity was determined for cells supplied with nitrogen and for nitrogen-deprived cells. For C. diphtheriae, no GS activity was detectable. This species has only a $g \ln A 2$ gene, which encodes a GSI $\alpha$-type glu- tamine synthetase, a situation comparable to a C. glutamicum glnA deletion strain. Also in C. glutamicum, GS activity was not observed in a $g \ln A 2$ background [Nolden et al., 2001b]. C. efficiens and C. glutamicum reveal an almost identical GS activity pattern. In nitrogen-rich medium, activity is low $(0.28 \pm 0.02 \mu \mathrm{mol}$ (mg protein $)^{-1} \mathrm{~min}^{-1}$ for C. efficiens and $0.07 \pm 0.04 \mu \mathrm{mol}(\mathrm{mg}$ protein $)^{-1} \mathrm{~min}^{-1}$ for C. glutamicum), while upon nitrogen starvation activity increases significantly to $0.86 \pm$ $0.28 \mu \mathrm{mol}$ (mg protein) ${ }^{-1} \mathrm{~min}^{-1}$ for C. efficiens and $0.67 \pm 0.10 \mu \mathrm{mol}(\mathrm{mg} \text { protein })^{-1} \mathrm{~min}^{-1}$ for C. glutamicum. Regulation most likely occurs on the level of transcription, controlled by AmtR, and on the level of activity, regulated by modification/demodification of GS via the $g \ln E$ gene product [Nolden et al., 2001b]. GS activity in C. jeikeium is low $\left(0.09 \pm 0.02 \mu \mathrm{mol}(\mathrm{mg} \text { protein })^{-1}\right.$ $\mathrm{min}^{-1}$ ) and under the experimental conditions used not regulated in response to the nitrogen supply.

\section{Modification of $G \ln K$}

In C. glutamicum, signal transduction protein $\mathrm{GlnK}$ is crucial for nitrogen control [Nolden et al., 2001a]. It is synthesized in response to nitrogen limitation, immediately adenylylated and in this form competent to interact with AmtR and induce transcription of nitrogen-controlled genes. When nitrogen supply improves, GlnK AMP is demodified to cease interaction with AmtR and to stop transcription of the AmtR regulon [Beckers et al., 2005]. Using C. glutamicum GlnK-specific antibodies, we tested GlnK synthesis and modification/demodification in C. diphtheriae, C. efficiens and C. jeikeium. Western blot experiments gave no immunoreaction with $C$. diphtheriae and C. jeikeium proteins (data not shown), either due to lack of cross-reactivity or of GlnK synthesis. For C. efficiens increasing synthesis of the protein upon starvation and demodification in response to ammonium addition was shown (fig. 3). Again, these results support the idea that nitrogen regulation is identical in C. glutamicum and C. efficiens.

\section{Concluding Remarks}

In this study, the available genomes sequences of corynebacteria were compared in respect to nitrogen metabolism and regulation. In general, nitrogen metabolism and control components are conserved among these species. However, specific differences were found. While the soil-living species C. efficiens and C. glutamicum have a broad set of genes coding for nitrogen source uptake systems, assimilatory enzymes and regulatory proteins, a clear tendency towards gene decay was observed for the 


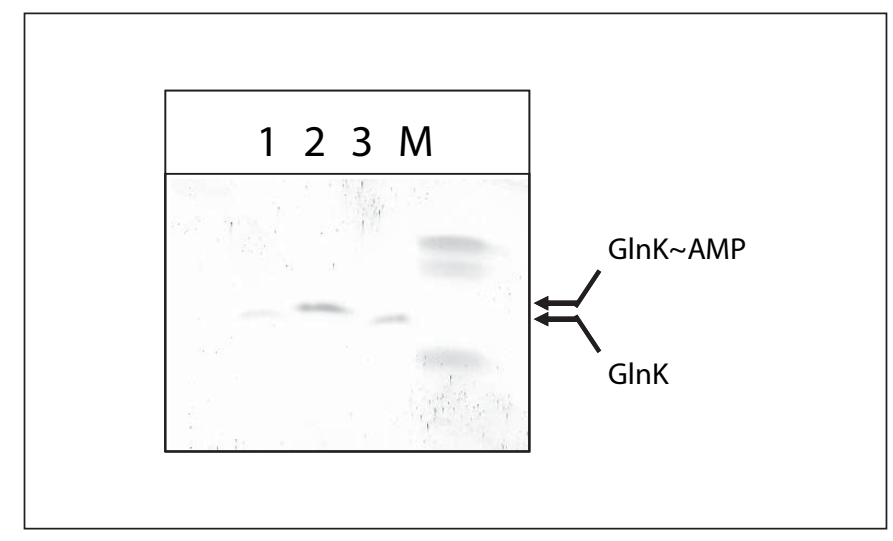

Fig. 3. Immunodetection of GlnK in C. efficiens. Cell extracts were prepared from cells grown in BHI medium (1), incubated for $1 \mathrm{~h}$ in nitrogen-free mineral salt medium (2) and after re-suspension of nitrogen-starved cells in BHI medium (3). Proteins were separated by SDS-PAGE, blotted and incubated with C. glutamicum GlnK-specific antiserum (M, marker proteins, from top to bottom: 24, 17 and $11 \mathrm{kDa}$ ).

pathogens C. diphtheriae and C. jeikeium. This includes ammonium and urea uptake systems, ammonium assimilation pathways, urea-cleaving enzymes and regulatory proteins like AmtR and GlnD. A similar tendency towards loss of genes in pathogenic bacteria was observed for mycobacteria. Especially Mycobacterium leprae shows a drastic gene reduction and decay compared for example to Mycobacterium smegmatis [Cole et al., 2001; Vissa and Brennan, 2001].

In C. diphtheriae, C. efficiens and C. glutamicum nitrogen-dependent gene expression seems to be controlled by the master regulator AmtR. Interestingly, not only the corresponding gene but also the DNA-binding motif of this global nitrogen regulator seems to be conserved during evolution. A similar result was obtained for the DtxR protein, which acts as a transcriptional regulator of iron metabolism in C. glutamicum. With the characterization of the DtxR box and analysis of DtxR-regulated genes and operons in C. glutamicum [Brune et al., 2006; Wennerhold and Bott, 2006], it was possible to predict corresponding binding motifs and regulons in C. diphtheriae, C. efficiens and C. jeikeium [Brune et al., 2006].

In summary, the screening of genomes for specific genes and transcriptional regulator-binding sites can give valuable information about physiology and uncharacterized metabolic pathways in different bacterial species.

\section{Experimental Procedures}

\section{Bacterial Strains and Growth}

C. diphtheriae DSM44123, C. efficiens YS-314 [Fudou et al., 2002] and C. glutamicum ATCC13032 [Abe et al., 1967] were cultivated in Brain Heart Infusion (BHI) while C. jeikeium K411 was grown in BYT medium [Tauch et al., 2004]. To induce nitrogen starvation, cells were harvested by centrifugation and re-suspended in CgXII minimal medium [Keilhauer et al., 1993], which was used without addition of ammonium and urea.

\section{Methylammonium Uptake}

Methylammonium uptake was measured as described [Siewe et al., 1996]. In brief, cells grown to the mid-log phase were harvested by centrifugation, washed with MES/Tris buffer (adjusted with $\mathrm{NaOH}$ to $\mathrm{pH} 8.0$ ), and suspended in the same buffer to a final $\mathrm{OD}_{600}$ of 3-4. Uptake measurements were started by the addition of 100,500 and $1,000 \mu \mathrm{M}\left[{ }^{14} \mathrm{C}\right]$-labeled methylammonium. Samples were taken in 15 -sec intervals over a period of $2 \mathrm{~min}$. Cells were separated from the surrounding medium by rapid filtration, washed twice, and subjected to scintillation counting. Experiments were carried out at least in duplicate and transport rates (mean \pm error) were calculated.

Glutamine Synthetase Activity

GS activities (mean $\pm \mathrm{SD}$ ) were determined as described [Jakoby et al., 1997] from three independent experiments.

\section{SDS-PAGE and Western Blotting}

Corynebacterium cells were disrupted using glass beads and a Q-BIOgene FastPrep FP120 instrument (Q-BIOgene, Heidelberg, Germany). Proteinase inhibitor (Complete, Roche, Basel, Switzerland) was added as recommended by the supplier. Protein concentrations were determined using a modified Lowry method [Dulley and Grieve, 1975]. SDS-PAGE was carried out as described [Schägger and von Jagow, 1987]. Gel-separated proteins (30 $\mu \mathrm{g} / \mathrm{lane})$ were transferred onto a polyvinylidene difluoride membrane by electroblotting and incubated with C. glutamicum GlnK-specific antiserum. Antibody binding was visualized by using anti-antibodies coupled to alkaline phosphatase and the BCIP/NBT alkaline phosphatase substrate.

\section{RNA Hybridization Experiments}

Probes for the analysis of $C$. jeikeium gene transcription were generated by PCR and subsequent labeling with DIG RNA-labeling mix and T7 polymerase (Roche, Mannheim, Germany). Oligonucleotide primers for the amplification of $0.3-\mathrm{kb}$ fragments (amtB: 5'-CCTCCGGAAATTCGGCTTGG-3'/5'-GGGCCCTAATACGACTCACTATAGGGGCCGATGTCGATGGCGTTGG3', gdh: 5'-CAGCGCAACGCGGGGGAG-3'/5'-GGGCCCTAATACGACTCACTATAGGGCTGGCAGTGTGAAGGGCTTG3', $g \ln A: \quad 5^{\prime}$-CGTCCGTGCGCGGCTTCA-3'/5'-GGGCCCTAATACGACTCACTATAGGGCCACCGATCGGCAGGCCG-3', $g \ln E:$ 5'-CGCGTTCCTCCGTGCCAAC-3'/5'-GGGCCCTAATACGACTCACTATAGGGGCTGCTTCCACTCCGCCG-3', gltB: 5'-CGTGTGGTGTCGCCTTTGTG-3'/ $5^{\prime}$-GGGCCCTAATACGACTCACTATAGGGGGTTCAGGCCCTCTTCCTCC-3', gltD: 5'-GGCTGATCCACGCGGATTTC-3'/5'-GGGCCCTAATACGACTCACTATAGGGCGGGTCATCGCCGATACCC-3'), chromosomal DNA as template and the following PCR program were 
used: $3 \mathrm{~min}$ at $94^{\circ} \mathrm{C}, 30$ cycles of $15 \mathrm{~s}$ at $94^{\circ} \mathrm{C}$ followed by $15 \mathrm{~s}$ at $60^{\circ} \mathrm{C}$ and $1 \mathrm{~min}$ at $72^{\circ} \mathrm{C}, 10 \mathrm{~min}$ at $72^{\circ} \mathrm{C}$, cooling to $4^{\circ} \mathrm{C}$.

For RNA preparation, bacteria were harvested by centrifugation, suspended in buffer (NucleoSpin ${ }^{h}$ RNA II-Kit, Macherey-Nagel, Düren, Germany) and immediately frozen in liquid nitrogen. Aliquots were thawed on ice and immediately disrupted using glass beads and a Q-BIOgene FastPrep FP120 instrument (QBIOgene, Heidelberg, Germany). After removal of cell debris, the RNA was isolated using the NucleoSpin ${ }^{h} R N A$ II-Kit following the recommendations of the supplier. The RNA was spotted onto nylon membranes using a Schleicher \& Schuell (Dassel, Germany) Minifold I Dot Blotter. Hybridization of digoxigenin-labeled
RNA probes was detected using Kodak X-OMAT X-ray films, alkaline phosphatase-conjugated anti-digoxigenin Fab fragments and CSPD as light-emitting substrate (Roche, Germany).

\section{Bioinformatics}

AmtR-binding sites were searched for in the $C$. diphtheriae and C. efficiens genomes by using the PredictRegulon web service (http://210.212.212.6/prindex.html [Yellaboina et al., 2004]) with the known binding sites from C. glutamicum [Beckers et al., 2005] as input sequences. The sequence logo plots in figure 1 were made with the SEQLOGO web service (http://ep.ebi.ac.uk/EP/SEQLO$\mathrm{GO} /$ ).

\section{References}

Abe, S., Takayama, K., Kinoshita, S. 1967. Taxonomical studies on glutamic acid-producing bacteria. J Gen Microbiol 13:279-301.

- Beckers, G., Nolden, L., Burkovski, A. 2001. Glutamate synthase of Corynebacterium glutamicum is not essential for glutamate synthesis and is regulated by the nitrogen status. Microbiology 147:2961-2970.

-Beckers, G., Bendt, A.K., Krämer, R., Burkovski, A. 2004. Molecular identification of the urea uptake system and transcriptional analysis of urea transporter- and urease-encoding genes in Corynebacterium glutamicum. J Bacteriol 186:7645-7652.

- Beckers, G., Strösser, J., Hildebrandt, U., Kalinowski, J., Farwick, M., Krämer, R., Burkovski, A. 2005. Regulation of AmtR-controlled gene expression in Corynebacterium glutamicum: mechanism and characterization of the AmtR regulon. Mol Microbiol 58:580595.

Bendt, A.K., Beckers, G., Silberbach, M., Wittmann, A., Burkovski, A. 2004. Utilization of creatinine as an alternative nitrogen source in Corynebacterium glutamicum. Arch Microbiol 181:443-450.

Börmann, E.R., Eikmanns, B.J., Sahm, H. 1992. Molecular analysis of the Corynebacterium glutamicum gdh gene encoding glutamate dehydrogenase. Mol Microbiol 6:317-326.

Brune, I., Brinkrolf, K., Kalinowski, J., Pühler, A., Tauch, A. 2005. The individual and common repertoire of DNA-binding transcriptional regulators of Corynebacterium glutamicum, Corynebacterium efficiens, $\mathrm{Co}$ rynebacterium diphtheriae and Corynebacterium jeikeium deduced from the complete genome sequences. BMC Genomics 6:86.

Brune, I., Werner, H., Hüser, A.T., Kalinowski, J., Pühler, A., Tauch, A. 2006. The DtxR protein acting as dual transcriptional regulator directs a global regulatory network involved in iron metabolism of Corynebacterium glutamicum. BMC Genomics 7:21.
Burkovski, A. 2003a. Ammonium assimilation and nitrogen control in Corynebacterium glutamicum and its relatives: an example for new regulatory mechanisms in actinomycetes. FEMS Microbiol Rev 27:617-628.

Burkovski, A. 2003b. I do it my way: Regulation of ammonium uptake and ammonium assimilation in Corynebacterium glutamicum. Arch Microbiol 179:83-88.

Burkovski, A. 2005. Nitrogen metabolism and its regulation. In: Bott, M., Eggeling, L. (Eds.) Handbook of Corynebacterium glutamicum. CRC Press LLC, Boca Raton, Fla., pp 333 349.

Cerdeno-Tarraga, A.M., Efstratiou, A., Dover, L.G., Holden, M.T.G., Pallen, M., Bentley, S.D., Besra, G.S., Churcher, C., James, K.D., De Zoysa, A., Chillingworth, T., Cronin, A., Dowd, L., Feltwell, T., Hamlin, N., Holroyd, S., Jagels, K., Moule, S., Quail, M.A., Rabbinowitch, E., Rutherford, K.M., Thomson, N.R., Unwin, L., Whitehead, S., Barrell, B. G., Parkhill, J. 2003. The complete genome sequence and analysis of Corynebacterium diphtheriae NCTC13129. Nucleic Acids Res 31:6516-6523.

Cole, S.T., Eiglmeier, K., Parkhill, J., James, K.D., Thomson, N.R., Wheeler, P.R., Honoré, N., Garnier, T., Churcher, C., Harris, D., Mungall, K., Basham, D., Brown, D. Chillingworth, T., Connor, R., Davies, R.M., Devlin, K., Duthoy, S., Feltwell, T., Fraser, A., Hamlin, N., Holroyd, S., Hornsby, T., Jagels, K., Lacroix, C., Maclean, J., Moule, S., Murphy, L., Oliver, K., Quail, M.A., Rajandream, M.-A., Rutherford, K.M., Rutter, S., Seeger, K., Simon, S., Simmonds, M., Skelton, J., Squares, R., Squares, S., Stevens, K., Taylor, K., Whitehead, S., Woodward, J.R., Barrell, B.G. 2001. Massive gene decay in the leprosy bacillus. Nature 409:1007-1011.

Dulley, J.R., Grieve, P.A. 1975. A simple technique for eliminating interference by detergents in the Lowry method of protein determination. Anal Biochem 64:136-141.
- Fudou, R., Jojima, Y., Seto, A., Yamada, K., Rimura, E., Nakamatsu, T., Hirashi, A., Yamanaka, S. 2002. Corynebacterium efficiens sp. Nov., a glutamic-acid-producing species from soil and plant material. Int J Syst Evol Microbiol 52:1127-1131.

Ikeda, M., Nakagawa, S. 2003. The Corynebacterium glutamicum genome: features and impacts on biotechnological processes. Appl Microbiol Biotechnol 62:99-109.

-Jakoby, M., Tesch, M., Sahm, H., Krämer, R., Burkovski, A. 1997. Isolation of the Corynebacterium glutamicum glnA gene encoding glutamine synthetase I. FEMS Microbiol Lett 154:81-88.

Jakoby, M., Krämer, R., Burkovski, A. 1999. Nitrogen regulation in Corynebacterium glutamicum: Isolation of genes involved and biochemical characterization of corresponding proteins. FEMS Microbiol Lett 173:303-310.

Jakoby, M., Nolden, L., Meier-Wagner, J., Krämer, R., Burkovski, A. 2000. AmtR, a global repressor in the nitrogen regulation system of Corynebacterium glutamicum. Mol Microbiol 37:964-977.

Kalinowski, J., Bathe, B., Bischoff, N., Bott, M., Burkovski, A., Dusch, N., Eggeling, L., Eikmanns, B.J., Gaigalat, L., Goesmann, A., Hartmann, M., Huthmacher, K., Krämer, R., Linke, B., McHardy, A.C., Meyer, F., Möckel, B., Pfefferle, W., Pühler, A., Rey, D., Rückert, C., Sahm, H., Wendisch, V.F., Wiegräbe, I., Tauch, A. 2003. The complete Corynebacterium glutamicum ATCC 13032 genome sequence and its impact on the production of L-aspartate-derived amino acids and vitamins. J Biotechnol 104:5-25.

Kalinowski, J. 2005. The genomes of amino acidproducing corynebacteria. In: Bott, M., Eggeling, L. (Eds.) Handbook of Corynebacterium glutamicum. CRC Press LLC, Boca Raton, Fla., pp 37-56.

Keilhauer, C., Eggeling, L., Sahm, H. 1993. Isoleucine synthesis in Corynebacterium glutamicum: molecular analysis of the ilvB$i l v N-i l v C$ operon. J Bacteriol 175:5595-5603. 
Lehmann, K.B., Neumann, R. 1896. Atlas und Grundriss der Bakteriologie und Lehrbuch der speziellen bakteriologischen Diagnostik. J.F. Lehmann, Munich, Germany.

-Meier-Wagner, J., Nolden, L., Jakoby, M., Siewe, R., Krämer, R., Burkovski, A. 2001. Multiplicity of ammonium uptake systems in $\mathrm{Co}$ rynebacterium glutamicum: Role of Amt and AmtB. Microbiology 147:135-143.

Nolden, L., Beckers, G., Möckel, B., Pfefferle, W., Nampoothiri, K.M., Krämer, R., Burkovski, A. 2000. Urease of Corynebacterium glutamicum: organization of corresponding genes and investigation of activity. FEMS Microbiol Lett 189:305-310.

Nolden, L., Ngouoto-Nkili, C.-E., Bendt, A.K., Krämer, R., Burkovski, A. 2001a. Sensing nitrogen limitation in Corynebacterium glutamicum: The role of $g \ln K$ and $g \ln D$. Mol Microbiol 42:1281-1295.

Nolden, L., Farwick, M., Krämer, R., Burkovski, A. 2001b. Glutamine synthetases in Corynebacterium glutamicum: transcriptional control and regulation of activity. FEMS Microbiol Lett 201:91-98.

Nolden, L., Beckers, G., Burkovski, A. 2002. Nitrogen assimilation in Corynebacterium diphtheriae: pathways and regulatory cascades. FEMS Microbiol Lett 208:287-293.
Puskás, L.G., Inui, M., Yukawa, H. 2000. Structure of the urease operon of Corynebacterium glutamicum. DNA Seq 11:383-394.

Schägger, H., von Jagow, G. 1987. Tricine-sodium dodecyl sulfate-polyacrylamide gel electrophoresis for the separation of proteins in the range from 1 to $100 \mathrm{kDa}$. Anal Biochem 166:368-379.

Schulz, A.A., Collett, H.J., Reid, S.J. 2001. Nitrogen and carbon regulation of glutamine synthetase and glutamate synthase in Corynebacterium glutamicum ATCC 13032. FEMS Microbiol Lett 205:361-367.

Siewe, R.M., Weil, B., Burkovski, A., Eikmanns, B.J., Eikmanns, M., Krämer, R. 1996. Functional and genetic characterization of the (methyl)ammonium uptake carrier of Corynebacterium glutamicum. J Biol Chem 271: 5398-5403.

Strösser, J., Lüdke, A., Schaffer, S., Krämer, R., Burkovski, A. 2004. Regulation of GlnK activity: modification, membrane sequestration, and proteolysis as regulatory principles in the network of nitrogen control in Corynebacterium glutamicum. Mol Microbiol 54: 132-147.
Tauch, A., Bischoff, N., Pühler, A., Kalinowski, J. 2004. Comparative genomics identified two conserved DNA modules in a corynebacterial plasmid family present in clinical isolates of the opportunistic human pathogen Corynebacterium jeikeium. Plasmid 52:102118.

Tauch, A., Kaiser, O., Hain, T., Goesmann, A., Weisshaar, B., Albersmeier, A., Bekel, T., Bischoff, N., Brune, I., Chakraborty, T., Kalinowski, J., Meyer, F., Rupp, O., Schneiker, S., Viehoever, P., Pühler, A. 2005. Complete genome sequence and analysis of the multiresistant nosocomial pathogen Corynebacterium jeikeium K411, a lipid-requiring bacterium of the human skin flora. J Bacteriol 187: 4671-4682.

Vissa, V.D., Brennan, P.J. 2001. The genome of Mycobacterium leprae: a minimal mycobacterial gene set. Genome Biology 2, reviews 1023.1-1023.8.

Wennerhold, J., Bott, M. 2006. The DtxR regulon of Corynebacterium glutamicum. J Bacteriol 188:2907-2918.

Yellaboina, S., Seshadri, J., Kumar, M.S., Ranjan, A. 2004. PredictRegulon: A web server for the prediction of the regulatory protein binding sites and operons in prokaryote genomes. Nucleic Acids Res 32:W318-W320. 